\title{
Minimum 10-Year Follow-up Study of Anterior Lumbar Interbody Fusion for Degenerative Spondylolisthesis: Progressive Pattern of the Adjacent Disc Degeneration
}

\author{
Masahiko Kanamori ${ }^{1,2}$, Taketoshi Yasuda ${ }^{2}$, Takeshi Hori ${ }^{2}$, Kayo Suzuki ${ }^{2}$, Yoshiharu Kawaguchi ${ }^{2}$ \\ ${ }^{1}$ Department of Human Science, University of Toyama, Toyama, Japan \\ ${ }^{2}$ Department of Orthopaedics, University of Toyama, Toyama, Japan
}

Study Design: Retrospective study.

Purpose: The aims of the current study are to evaluate the minimum 10-year follow-up clinical results of anterior lumbar interbody fusion (ALIF) for degenerative spondylolisthesis.

Overview of the Literature: ALIF has been widely used as a treatment regimen in the management of lumbar spondylolisthesis. Still much controversy exists regarding the factors that affect the postoperative clinical outcomes.

Methods: The author performed a retrospective review of 20 patients with degenerative spondylolisthesis treated with ALIF (follow-up,16.4 years). The clinical results were assessed by the Japanese Orthopaedic Association (JOA) score for low back pain, vertebral slip and disc height index on the radiographs.

Results: The mean preoperative JOA score was $7.1 \pm 1.8$ points (15-point-method). At 1 year, 5 years, and 10 years or more after surgery, the JOA scores were assessed as $12.4 \pm 2.2$ points, $12.7 \pm 2.6$ points, $12.0 \pm 2.5$ points, respectively (excluding the data of reoperated cases). The adjacent disc degeneration developed in all cases during the long-term follow-up. The progressive pattern of disc degeneration was divided into three types. Initially, disc degeneration occurred due to disc space narrowing. After that, the intervertebral discs showed segmental instability with translation at the upper level. But the lower discs showed osteophyte formation, and occasionally lead to the collapse or spontaneous union.

Conclusions: The clinical results of the long-term follow-up data after ALIF became worse due to the adjacent disc degeneration. The progressive pattern of disc degeneration was different according to the adjacent levels.

Key Words: Spondylolisthesis, Lumbar regions, Intervertebral disc disease

\section{Introduction}

Degenerative spondylolisthesis may occur as a result of one or more of the following causes: degenerative changes in discs, facet joints, and ligamentous structure, disc herniation, or previous surgical intervention. The aim of surgical treatment of degenerative spondylolisthesis should be to provide an early relief of symptoms and long-term effectiveness. If conservative treatment is ineffective, the most common surgical procedure is spinal fusion combined with decompression of the neural elements. Recent surgical trends for this pathology are spinal fusion and decompression of the spinal segment by means of the instrumentation technique. Herkowitz and Kurz [1] stated that the patients who underwent the combined fusion and decompression operation had better results than those who underwent decompression alone. In contrast, several investigators have found a little difference in the results between the patients

Received Jun 30, 2011; Revised Oct 11, 2011; Accepted Oct 26, 2011

Corresponding author: Masahiko Kanamori, MD, PhD

Department of Human Science, Department of Orthopaedics, University of Toyama, 2630 Sugitani, Toyama 930-0194, Japan

Tel: +81-76-434-7405, Fax: +81-76-434-5186, E-mail: kanamori@med.u-toyama.ac.jp

Copyright (C) 2012 by Korean Society of Spine Surgery

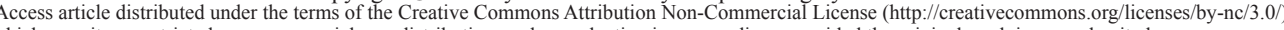
which permits unrestricted non-commercial use, distribution, and reproduction in any medium, provided the original work is properly cited. Asian Spine Journal • pISSN 1976-1902 eISSN 1976-7846 
who underwent fusion and those who did not undergo fusion $[2,3]$.

Many follow-up studies of posterolateral fusion or posterior lumbar interbody fusion (PLIF) have been reported [47]. On the other hand, only a few have focused on anterior lumbar interbody fusion (ALIF) for spondylolisthesis [8-10]. Since 1981, ALIF has been the preferred surgical method at our department, because ALIF is a reasonable method from the view point of the biomechanics of degenerative spondylolisthesis. We performed direct decompression of the dura via discectomy, according to the Tsuji [11] method . Satisfactory nerve root decompression may be achieved via total discectomy and restoration of intervertebral height, followed by anterior insertion of interbody grafts [12-14].

The aims of the current study were to evaluate the longterm clinical and radiologic results after ALIF for degenerative spondylolisthesis with spinal stenosis and to assess the underlying mechanism of the postoperative adjacent disc disease.

\section{Materials and Methods}

\section{Patient demographics}

Between 1981 and 1992, a total of 28 patients underwent ALIF for degenerative spondylolisthesis with spinal stenosis. Of these, 20 patients were followed clinically and radiographically for more than 10 years (final follow-up rate, $71.4 \%$ ). There were 6 male and 14 female patients, and their average age at surgery was $58.0 \pm 7.2$ years (range, 44 to 70 years). All patients had spondylolisthesis of $3 \mathrm{~mm}$ or more, without spondylolysis. Moreover, their myelograms showed a complete or an incomplete block.

The average length of the follow-up period was 17.1 years (range, 10.9 to 23.3 years). Degenerative spondylolisthesis occurred at the L3 level in 5 cases, and the L4 level in 15 cases.

\section{Surgical procedures and aftercare program}

Operative intervention was indicated when conservative management consisting of rest, physiotherapy, or antiinflammatory medications failed to alleviate the symptom complex of leg pain, intermittent claudication, and neurological changes associated with spondylolisthesis.

During surgery, the extraperitoneal approach through an oblique abdominal skin incision was used, allowing the skin to be pulled down to the level beyond the left iliac crest. Three thick cortico-cancellous bone grafts were harvested from the inner table of the left iliac bone, followed by total discectomy and bone grafting. We performed direct decompression of the dura via discectomy. In total discectomy, we removed the anterior/ posterior annulus fibrosus and posterior longitudinal ligament as much as possible, according to the Tsuji [11] method. ALIF is a reasonable approach to correct spinal malalignment in anterior spondylolisthesis, because anterior translation in anterior flexion and a greater tilt of the vertebra are observed. Bone grafts were impacted as firmly as possible $[11,15,16]$.

After ALIF, ceramic interspinous block (CISB) insertion was performed in the lateral position. The CISB provides early stabilization of the posterior lamina, and can prevent the separation of the anterior graft-vertebra bone interfaces, which increases the union ratio $[11,15,16]$. Briefly, a small median skin incision was made just above the interspinous level identical to the level of ALIF. The supraspinous ligament was removed, followed by minimal resurfacing of adjacent margins of the spinous processes using an appropriately sized dual chisel. The CISB was firmly inserted into the interspinous space using an original inserter.

The patient began walking with a body cast or a flame corset from 2 weeks after surgery. The cast application period was 4 to 6 weeks, followed by return to work with a short or soft lumbar support.

\section{Clinical assessment}

Preoperative clinical data were obtained from the medical records and preoperative radiographs (posteroanterior/ lateral lumbosacral spine series). Operation data were also reviewed. Follow-up evaluation was performed via clinical visits. The Japanese Orthopaedic Association score (JOA score) for low back pain (JOA score, 15-point-method) was used to evaluate the clinical outcome according to the previous paper [17]. The items of subjective symptoms ( 9 points: low back pain, leg pain, and walking ability), clinical signs (6 points: sensory and motor disturbance, the angle of positive straight leg raising test) were evaluated. A completely normal condition would receive 15 points as is the total of the best score. The postoperative improvement rate was determined by the equation mentioned in Table 1. Moreover, a survival curve was generated using the Kaplan-Meier method [18]. 
Table 1. The Japanese Orthopaedic Association's (JOA) score (15-point-method)

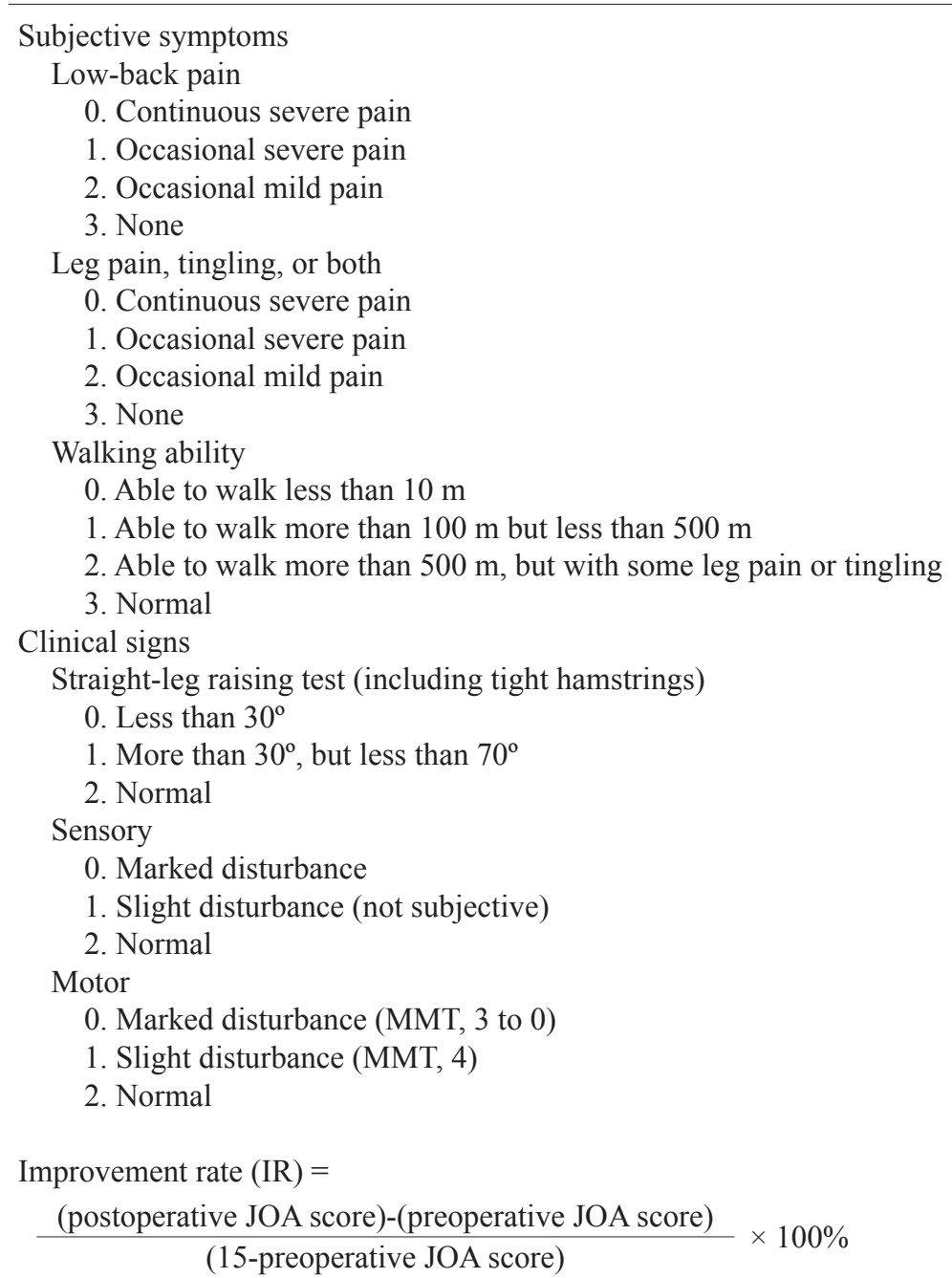

MMT: Manual muscle testing.

\section{Radiological assessment}

Radiologic analysis was based on the following radiologic items: vertebral slip and disc space narrowing. These parameters were measured before and after surgery. In a lateral radiograph taken with the patient in the standing position, the vertebral slip was measured using the Taillard's method [19]. The intervertebral disc height was expressed as the ratio of the disc height index according to the previous study [20-22]. Briefly, this parameter was assessed by the sum of measurements of the anterior and posterior height of the disc to the anteroposterior diameter of the underlying vertebral body (Fig. 1). The union of the grafted bone was evaluated by a series of radiographs or tomograms according to the methods mentioned in the previous report [17]. The interbody graft union was evaluated by distinct new bone formation at the anterior/posterior margins of the graft.

The postoperative adjacent disc degeneration was defined as intervertebral disc narrowing of more than $10 \%$ of the disc height index, and/or the progression of the vertebral slip ( $2 \mathrm{~mm}$ or more), compared with that on the preoperative radiographs. These criteria were based on the previous report [20-22]. Based on these data, we classified the progressive pattern of the adjacent disc degeneration into three types; disc space narrowing (DSN), segmental instability with translation (SIT), or collapse or spontaneous union (CSU).

\section{Statistical analysis}

The results are expressed as the mean \pm standard deviation. A $p$-value less than 0.05 was considered statistically 
significant. Statistical analyses (Student's $t$-test, chi-square test) were performed using StatMate III software (Atoms Co., Tokyo, Japan).

\section{Results}

\section{Clinical results and time course}

Before the operation, all the patients had leg symptoms, such as radicular leg pain, numbness, or intermittent claudication. Bilateral leg symptoms were observed in 16 patients, and unilateral symptoms were observed in 4 patients, preoperatively. These radiculopathies occurred predominantly

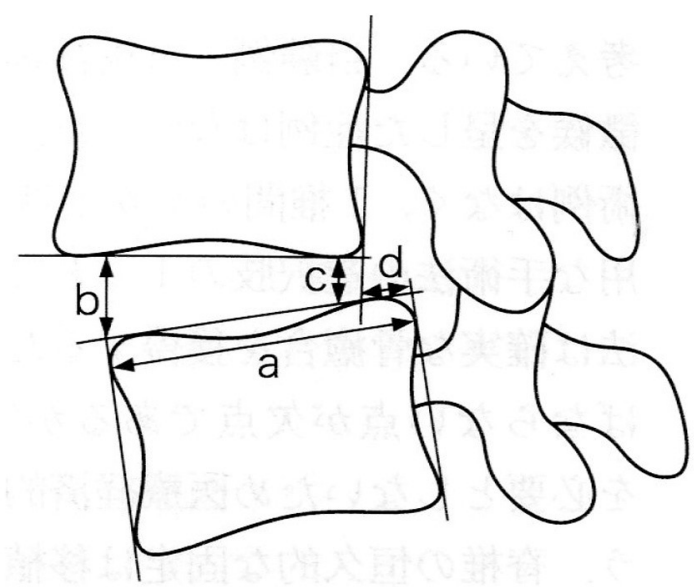

Fig. 1. The intervertebral disc height was measured. To correct for the magnification of the radiograph, the intervertebral disc height is expressed as the percentage of the total disc height to the longitudinal diameter of the vertebral body using the formula $[(\mathrm{b}+\mathrm{c}) / \mathrm{a} \times 100]$. $\mathrm{d}$ : Distance of olisthesis.

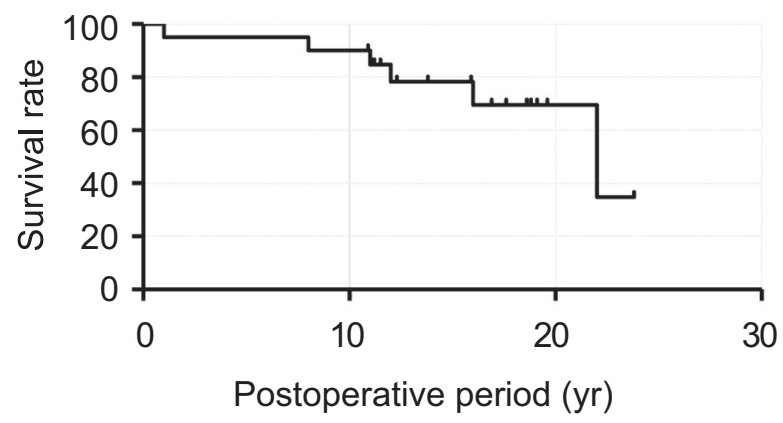

Fig. 2. Kaplan-Meier survival curve. The overall cumulative percentage of patients with satisfactory results is shown. in the L5 roots. Urinary disturbance was observed in 7 patients. All patients were followed up for a minimum of 10 years after the surgery.

The mean preoperative JOA score was $7.1 \pm 1.8$ points. At 1 year, 5 years, and 10 years or more (at the final examination) after surgery, the mean JOA scores were $12.4 \pm$ 2.2 points, $12.7 \pm 2.6$ points, $12.0 \pm 2.5$ points, respectively (excluding the data of the reoperated cases). From the graph of the Kaplan-Meier method, the final clinical results (after 10 years or more) had obviously worsened. In the long-term follow-up, six patients ( $30 \%$ of total cases) were required to undergo a salvage operation due to the adjacent disc degeneration. Although, ALIF seemed to provide satisfactory overall clinical results in the mid-term (until 10 years), clinical results of the long-term follow-up data became worse because of deterioration symptoms due to adjacent spinal stenosis (Fig. 2).

\section{Radiologic results}

All patients had anterior spondylolisthesis. Myelograms of all the patients demonstrated spinal canal stenosis at the spondylolisthetic levels. The mean vertebral slip was 9.1 $\pm 3.9 \mathrm{~mm}$ (range, 3 to $20 \mathrm{~mm}$ ) and the average percentage of vertebral slip was $17.8 \pm 5.3 \%$ (range, 6 to $50 \%$ ) by the

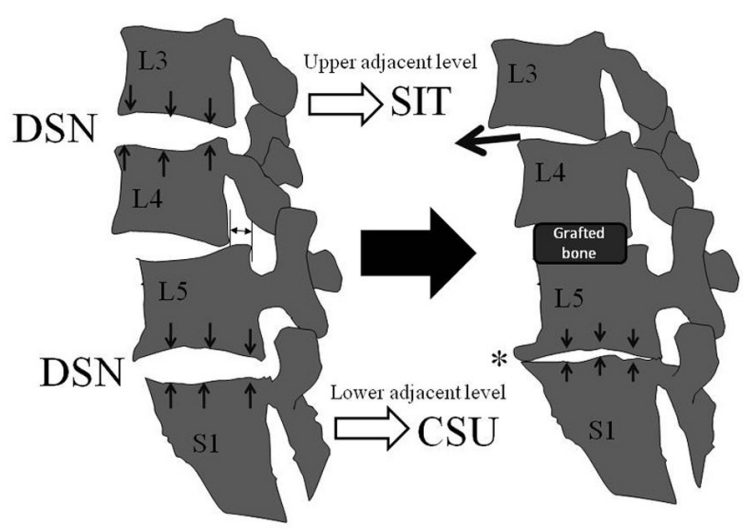

Fig. 3. The schema of the adjacent disc disease after fusion surgery. The progressive pattern of disc degeneration is different according to the adjacent levels (upper level or lower level). Initially, disc degeneration occurred due to the disc space narrowing (DSN). Thereafter at the upper level, the intervertebral disc showed anterior/posterior spondylolisthetic changes (segmental instability with translation, SIT). But, at the lower level, it showed osteophyte formation, and occasionally leads to fusion (collapse or spontaneous union, CSU). 
Table 2. Progressive pattern of adjacent disc degeneration

\begin{tabular}{|c|c|c|c|c|c|c|c|c|c|}
\hline \multirow{2}{*}{ No. } & \multirow{2}{*}{$\begin{array}{l}\text { Age/ } \\
\text { sex }\end{array}$} & \multirow{2}{*}{$\begin{array}{c}\text { Olisthesis } \\
\text { level }\end{array}$} & \multirow{2}{*}{$\begin{array}{l}\text { Preoperative } \\
\text { (\%slip) }\end{array}$} & \multirow{2}{*}{$\begin{array}{l}\text { Fusion } \\
\text { level }\end{array}$} & \multirow{2}{*}{$\begin{array}{l}\text { Follow-up } \\
\quad(\mathrm{yr})\end{array}$} & \multicolumn{2}{|c|}{$\begin{array}{l}\text { Progressive pattern of } \\
\text { adjacent disc degeneration }\end{array}$} & \multicolumn{2}{|c|}{ Salvage operation } \\
\hline & & & & & & Upper level & Lower level & Level & $\begin{array}{l}\text { Pop-term } \\
\text { (yr) }\end{array}$ \\
\hline 1 & $56 / \mathrm{F}$ & L4 & 34.0 & L4-5 & 11.1 & DSN & DSN & - & - \\
\hline 2 & $60 / \mathrm{M}$ & L4 & 9.3 & L4-5 & 15.9 & DSN & DSN & - & - \\
\hline 3 & $55 / \mathrm{F}$ & L4 & 28.0 & L3-5 & 18.6 & DSN & DSN & - & - \\
\hline 4 & $55 / \mathrm{F}$ & L4 & 29.0 & L4-5 & 19.1 & DSN & DSN & - & - \\
\hline 5 & $65 / \mathrm{F}$ & L4 & 24.3 & L3-5 & 18.3 & SIT & $\mathrm{CSU}$ & $\bullet(\mathrm{U}+\mathrm{L})$ & 12 \\
\hline 6 & $62 / \mathrm{M}$ & L3 & 15.2 & L3-5 & 16.9 & DSN & DSN & - & - \\
\hline 7 & $55 / \mathrm{F}$ & L3 & 20.0 & L3-5 & 11.5 & - & DSN & - & - \\
\hline 8 & $60 / \mathrm{M}$ & L4 & 16.3 & L4-5 & 18.8 & DSN & DSN & - & - \\
\hline 9 & $56 / \mathrm{F}$ & L3 & 15.9 & L3-4 & 13.8 & DSN & DSN & - & - \\
\hline 10 & $49 / \mathrm{F}$ & L3 & 26.0 & L4-5 & 22.0 & DSN & DSN & $\bullet(\mathrm{U}+\mathrm{L})$ & 22 \\
\hline 11 & $57 / \mathrm{M}$ & L4 & 14.3 & L4-5 & 17.6 & - & DSN & - & - \\
\hline 12 & $50 / \mathrm{F}$ & L3 & 13.6 & L3-4 & 19.5 & SIT & DSN & $\begin{array}{l}\bullet(\mathrm{L}) \\
\bullet(\mathrm{U})\end{array}$ & $\begin{array}{l}11 \\
18\end{array}$ \\
\hline $13^{\mathrm{a})}$ & $53 / \mathrm{F}$ & L4 & 17.5 & L4-5 & 25.0 & SIT & $\mathrm{CSU}$ & - & - \\
\hline 14 & $62 / \mathrm{M}$ & L4 & 20.8 & L4-5 & 16.9 & DSN & $\mathrm{CSU}$ & $\bullet(\mathrm{U})$ & 1 \\
\hline 15 & $47 / \mathrm{F}$ & L4 & 50.0 & L4-5 & 20.2 & DSN & DSN & $\begin{array}{l}\bullet \circ(\mathrm{U}) \\
\bullet \circ(\mathrm{U}+\mathrm{L})\end{array}$ & $\begin{array}{c}8 \\
19\end{array}$ \\
\hline 16 & $42 / \mathrm{F}$ & L4 & 24.0 & L4-5 & 12.3 & DSN & $\mathrm{CSU}$ & - & - \\
\hline 17 & $57 / \mathrm{F}$ & L4 & 24.4 & L4-5 & 11.2 & DSN & $\mathrm{CSU}$ & - & - \\
\hline 18 & $53 / \mathrm{F}$ & L4 & 35.0 & L4-5 & 10.9 & DSN & DSN & - & - \\
\hline 19 & $52 / \mathrm{F}$ & L4 & 25.0 & L4-5 & 19.6 & SIT & $\mathrm{CSU}$ & - & - \\
\hline $20^{a)}$ & $44 / \mathrm{M}$ & L4 & 6.4 & L4-5 & 23.3 & SIT & $\mathrm{CSU}$ & (U) & 16 \\
\hline
\end{tabular}

The abbreviation of the progressive pattern of the postoperative adjacent disc degeneration after anterior lumbar interbody fusion.

Pop: Postoperative, DSN: Disc space narrowing, SIT: Segmental instability with translation, CSU: Collapse or spontaneous union, $\bullet$ : Required the salvage operation due to the adjacent disc degeneration, $\circ$ : Equired the fusion surgery (case \#15 required the decompression and fusion surgery for the adjacent disc degeneration, but resulted in nonunion after the 2nd operation. After that, this case required the salvage operation once more), U: Upper adjacent disc level, L: Lower adjacent disc level.

${ }^{\text {a) }}$ Case \#13 and \#20 are described as representative cases (Figs 4 and 5).

Taillard's method [19]. After surgery, the mean vertebral slip was decreased to $7.0 \pm 4.4 \mathrm{~mm}(12.2 \%, p<0.05)$, and it was maintained until the final follow-up $(7.0 \pm 4.4 \mathrm{~mm}$, $12.0 \% ; p<0.05)$. The mean preoperative intervertebral disc height index at the spondylolisthetic level was $0.41 \pm 0.10$. At 1 year after surgery, the disc height index was $0.43 \pm 0.09$ and it was maintained until the final follow-up (disc height index, $0.42 \pm 0.09$ ). We measured the lumbar lordosis (L1L5) on the X-rays, both preoperatively and postoperatively. Preoperatively, the average lumbar lordosis was $-0.8 \pm 8.96$.
However postoperatively, the average lumbar lordosis was $4.85 \pm 6.05$. There was an increase in lordosis in $12 / 20$ cases, postoperatively.

However, the adjacent disc degeneration was observed in all cases. Although, upper adjacent level degeneration was observed in 18 cases ( $90 \%$ of total cases), lower adjacent disc degeneration was observed in all cases. No cases had only upper disc degeneration. The initial stage of disc degeneration was DSN. However after that, the progressive pattern of disc degeneration was different according to 
the adjacent levels (upper level or lower level). At the upper level, the intervertebral disc showed spondylolisthetic changes (SIT). But the lower discs had osteophyte formation, and occasionally lead to CSU (Fig. 3). The lower level corresponded to the L5-S1 level in 18 of 20 cases, because ALIF was mainly performed at the L4-5 level. Salvage surgeries were mainly performed at the upper level, at an average of 11.7 years postoperatively (Table 2 ).

\section{Illustrative cases}

\section{1) Case 1}

A 53-year-old woman presented with bilateral leg and low back pain. The preoperative JOA score was 4 points. A radiograph showed L4 degenerative spondylolisthesis $(17.5 \%)$, and an intervertebral disc height index of 0.13 . After ALIF, the percentage of vertebral slip was decreased to $11.8 \%$, and the intervertebral disc height was increased to 1.47 . The deterioration of the vertebral slip and collapse of grafted bone gradually occurred, but complete union of interbody graft was achieved. At the latest follow-up (25.0 years after surgery), adjacent disc degeneration was observed at both the levels on the radiographs and magnetic resonance imaging (MRI). She reported an occasional low back pain. The upper adjacent disc height index (L3-4) was decreased from 0.43 to 0.26 (decreased ratio, $39.5 \%$ ) on the plain radiograph. The progressive pattern of was SIT. However, at the lower disc level (L5-S) the collapse of the disc space was observed. The progressive pattern of disc degeneration was CSU (Fig. 4).

\section{2) Case 2}

A 44-year-old man reported experiencing low back and bilateral leg pain (in the L5 area). The preoperative JOA score was 10 points. Lumbar spine radiographs showed L4 degenerative spondylolisthesis, (vertebral slip, 6.4\%) and an intervertebral disc height of 0.32. After ALIF at L4-5, the vertebral slippage disappeared, and the intervertebral disc height index increased to 1.56. After 16 years, segmental stenosis occurred at the upper disc level (L3-4). This segment showed symptomatic SIT. So the patient underwent the PLIF surgery using instrumentation. At the latest followup, 23.3 years after initial surgery, radiographs and MRI showed adjacent disc degeneration at the next level (DSN at L2-3). The disc height index of L2-3 was decreased from 0.52 to 0.31 (decreased ratio, 40.4\%). The disc level (L5-S1) lower to the ALIF showed the changes of CSU. He reported experiencing an occasional low back pain, but there was a limited disability (Fig. 5).

\section{Discussion}

The characteristic observation in spondylolisthesis includes anterior collapse of disc space. Therefore, it is generally an indication for spinal fusion in an extended position, through the restoration of disc height and vertebral slip.
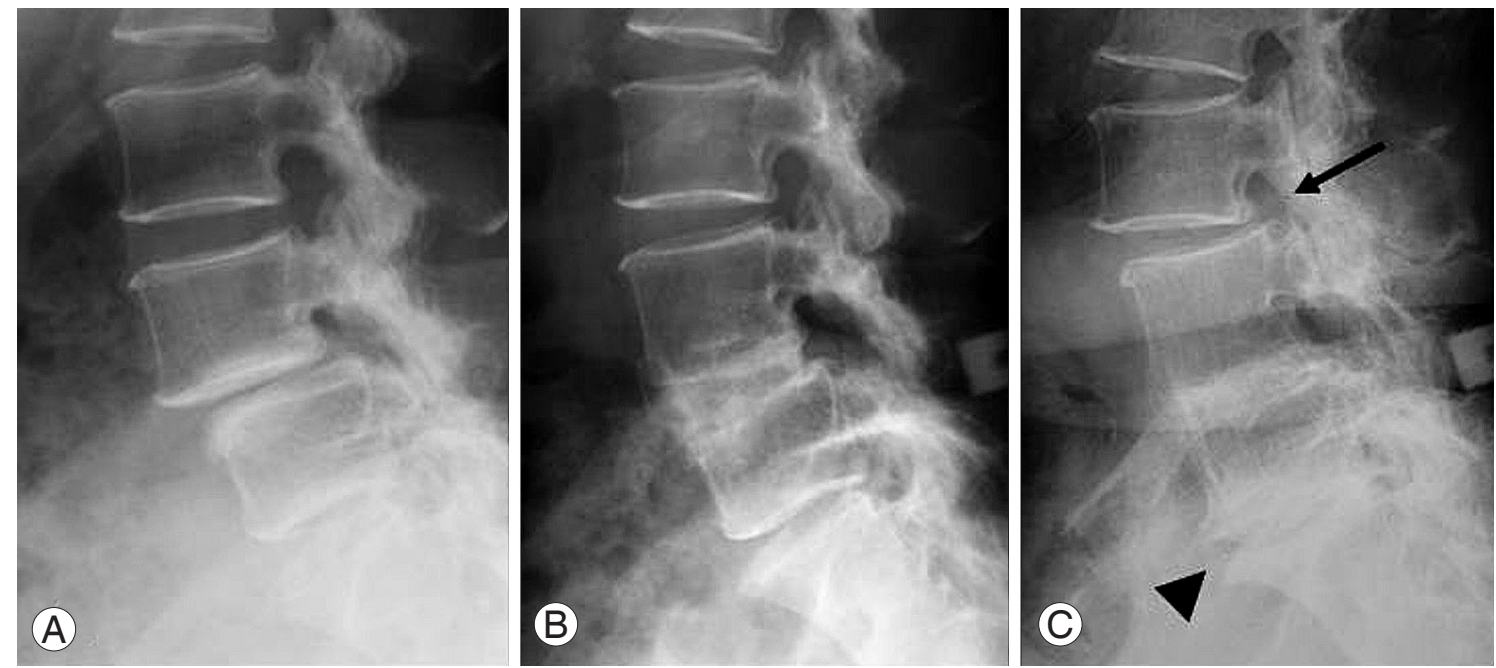

Fig. 4. A 53-year-old woman with L4 spondylolisthesis. (A) A preoperative lateral radiograph shows a vertebral slip of $18 \%$ and intervertebral disc index of 0.13 at L4-5. (B) An 8-year postoperative radiograph shows complete union. The ceramic interspinous block is seen in the interlaminar space. (C) Adjacent disc degeneration is observed in a 16-year postoperative radiograph. The upper disc (L3-4) shows anterior vertebral slip of $16.7 \%$ (arrow). The lower disc (L5-S1) shows osteophyte formation and collapse (arrow head). 
Table 3. Comparison of the surgical results of ALIF between spondylolisthesis and spondylolysis

\begin{tabular}{|c|c|c|}
\hline & Spondylolisthesis (present study) & Spondylolysis (Ishihara's study) \\
\hline Cases & 20 & 23 \\
\hline Average age (yr) & $58.0(44-70)$ & $38.0(16-57)$ \\
\hline Sex & Male 6, Female 14 & Male 19, Female 4 \\
\hline Follow-up rate (\%) & 70.0 & 65.7 \\
\hline Follow-up period (yr) & 15.6 & 13.3 \\
\hline Level & L4:16, L5:4 & L3:1, L4:9, L5:13 \\
\hline Reoperated cases & $6(30.0 \%)$ & $0(0 \%)$ \\
\hline \multicolumn{3}{|l|}{ JOA score (points) } \\
\hline Preoperation & $7.1 \pm 1.8$ & $9.7 \pm 2.2$ \\
\hline Postoperation $1 \mathrm{yr}$ & $12.4 \pm 2.2$ & $13.6 \pm 2.1$ \\
\hline Postoperation $5 \mathrm{yr}$ & $12.7 \pm 2.6$ & $13.9 \pm 1.1$ \\
\hline Postoperation $10 \mathrm{yr}$ & $12.0 \pm 2.5$ & $13.8 \pm 1.2$ \\
\hline \multicolumn{3}{|l|}{ Adjacent disc degeneration } \\
\hline \multicolumn{3}{|l|}{ Total cases } \\
\hline Upper level & $18 / 20(90.0 \%)^{\mathrm{a})}$ & $8 / 23(34.8 \%)$ \\
\hline Lower level & $20 / 20(100 \%)^{b)}$ & $7 / 10(70.0 \%)$ \\
\hline \multicolumn{3}{|l|}{ DSN type } \\
\hline Upper level & $13 / 20(65.0 \%)^{\mathrm{a})}$ & $2 / 23(8.7 \%)$ \\
\hline Lower level & $13 / 20(65.0 \%)$ & $6 / 10(60.0 \%)$ \\
\hline \multicolumn{3}{|l|}{ SIT type } \\
\hline Upper level & $5 / 20(25.0 \%)$ & $6 / 23(26.1 \%)$ \\
\hline Lower level & $0 / 20(0 \%)$ & $1 / 10(10.0 \%)$ \\
\hline \multicolumn{3}{|l|}{ CSU type } \\
\hline Upper level & $0 / 20(0 \%)$ & $0 / 23(0 \%)$ \\
\hline Lower level & $7 / 20(35.0 \%)^{\mathrm{c})}$ & $0 / 10(0 \%)$ \\
\hline
\end{tabular}

The data of Ishihara's study are quoted from the previous our report [7].

The abbreviation of the progressive pattern of the postoperative adjacent disc degeneration after anterior lumbar interbody fusion.

ALIF: Anterior lumbar interbody fusion, JOA: Japanese Orthopaedic Association, DSN: Disc space narrowing, SIT: Segmental instability with translation, CSU: Collapse or spontaneous union.

The data of adjacent disc degeneration were statistically compared with spondylolysis (chi-square test: ${ }^{\text {a) }} p<0.001,{ }^{\text {b) }} p<0.01$, ${ }^{c} p<0.05$ ). The rate of postoperative adjacent disc degeneration was statistically high in the item of total cases, DSN type (upper level) and CSU type (lower level) in the spondylolisthesis group (present study).

ALIF is one of the reasonable surgical methods for this pathology [11]. Dennis et al. [23] investigated the disc height after ALIF using autogeneous, cadaver, or mixed iliac crest grafts. They found that $46 \%$ of levels were actually narrower than their preoperative heights. Kumar et al. [24] also investigated the subsequent behavior of the disc height after ALIF with femoral strut allograft. Disc height was main- tained only in $59 \%$ of cases. The disc degeneration in spondylolisthesis is considered to be more severe than that in any other disc pathology, such as herniation, spondylolysis, and so on.

We compared the clinical results of ALIF for spondylolisthesis and for isthmic spondylolisthesis, which we had previously reported (Table 3). The long-term follow-up result 
of ALIF for spondylolisthesis was worse, and the rate of adjacent disc degeneration was high. Moreover, we performed repeated surgery for adjacent disc degeneration in 6 cases $(30 \%)$ of this series (present study). One of the reasons for this is the older age population. These patients had severe multi-level disc degeneration and ligament hypertrophy before the initial surgery. Therefore, decompressive laminectomy combined with some type of spinal fusion seems to be beneficial for the treatment of degenerative spondylolisthesis. However, an additional fusion surgery is not always required in case of degenerative spondylolisthesis without symptomatic instability.

Most patients presented with lower leg symptoms, such as radicular leg pain, numbness, or intermittent claudication. In case of spinal stenosis associated with spondylolisthesis (Meyerding type I) [25], we performed decompressive surgery alone [20]. Several authors have advised that fusion surgery should be performed only as a second stage procedure whenever necessary [3]. The indications for ALIF are controversial: our indications for ALIF were Meyerding type II or more, and Meyerding type I with instability (symptomatic and dynamic). Symptomatic instability means severe low back pain or stiffness induced by body motion or manual labor. Most of the patients experience morning stiffness in the low back, or apprehension, frequently. Dynamic instability indicates an abnormal range of motion or transla-
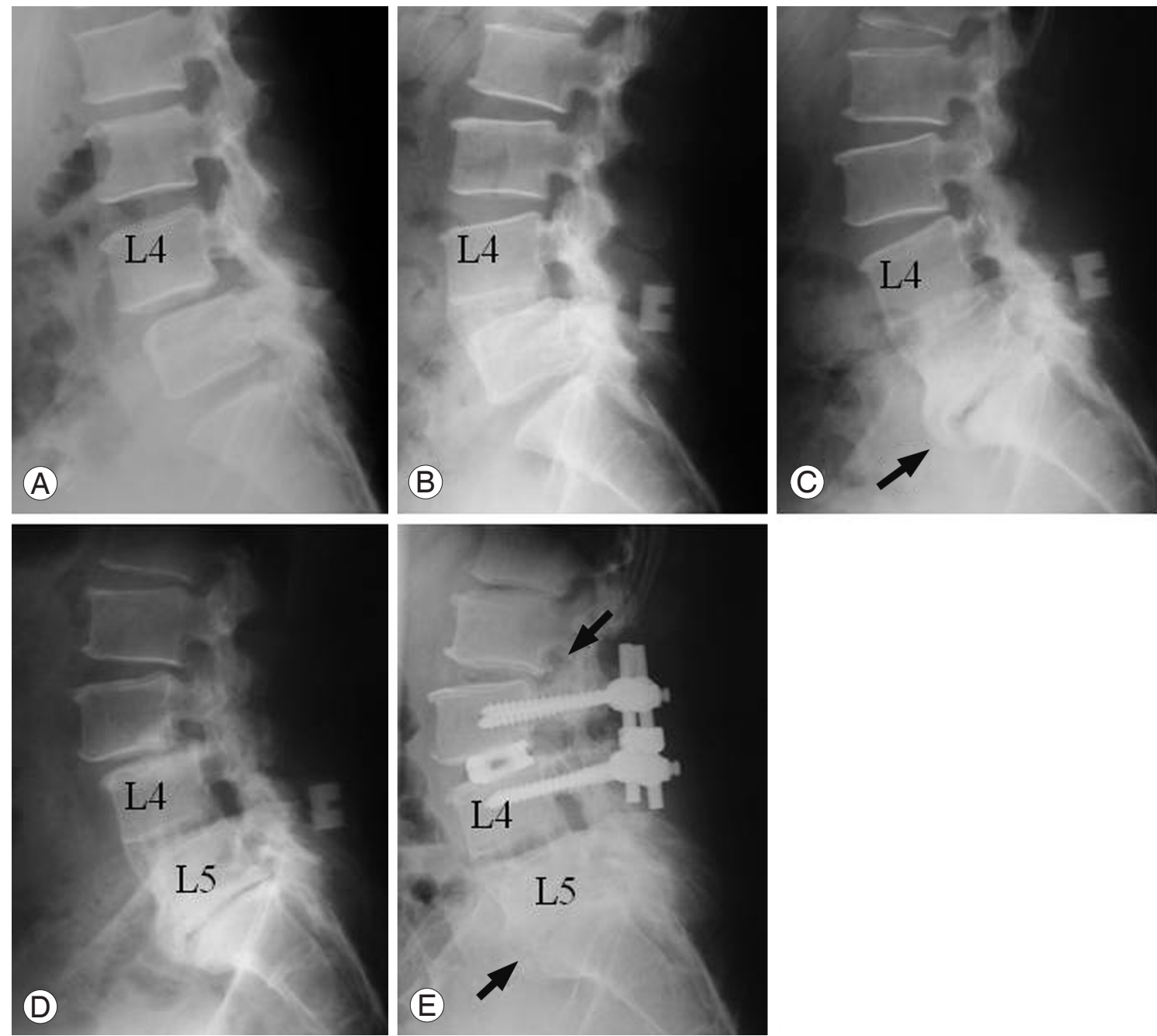

Fig. 5. A 44-year-old man with L4 spondylolisthesis. (A) A preoperative lateral radiograph shows a vertebral slip of $6.4 \%$ and intervertebral disc index of 0.32 at L4-5. (B) A 4-year postoperative radiograph shows complete union. The ceramic interspinous block is seen in the interlaminar space. (C) A 12-year postoperative radiograph shows osteophyte formation and collapse (L5-S1, arrow head). But he had no symptoms. (D) A 16year postoperative radiograph shows L3-4 anterior slip (12.2\%). He experienced recurrent low back pain, and an additional fusion surgery at L3-4 was required. (E) We performed posterior lumbar interbody fusion at L3-4. However, the next adjacent disc slip (L2-3, 17.4\%) is seen (small arrow). The lower disc shows complete union without operation (big arrow). 
tion on the lateral flexion-extension radiographs. Panjabi and White [26] stated that translation of 10 degrees or more at L4-5, or 15 degrees or more at L5-S1 indicated radiological instability. Moreover, abnormal translation of about 2 $\mathrm{mm}$ or more is detectable on the plain radiographs. Johnsson et al. [27] stated that pre- and postoperative olisthesis of less than $2 \mathrm{~mm}$ should not be counted. According to their criteria, we assessed the dynamic instability on the plain radiograph. We have performed ALIF in cases with these pathologies [11].

In the treatment of degenerative spondylolisthesis with symptomatic or dynamic instability, fusion surgery including ALIF is necessary and important. Takahashi [10] reported that the patients generally maintained satisfactory results up to 65 years of age. To date, the problem of the adjacent disc degeneration after spinal fusion has been pointed out $[28,29]$. Biomechanical data suggested that the mobility and the intradiscal pressure of the adjacent discs were increased after single-level fusion [8]. Clinically, adjacent disc degeneration has been implicated as a cause of low back pain. Rahm and Hall [29] reported that adjacent disc degeneration occurred in $35 \%$ of patients and was associated with worsening of clinical results with time. But, Seitsalo et al. [30] showed that spinal fusion did not significantly increase the rate of adjacent disc degeneration after a mean period of 13.8 years. They found no correlation between the number of degenerated discs or the degree of degeneration and subjective low back pain symptoms. It is important to clarify the cause of recurrent low back pain after ALIF, in order to improve the long-term clinical results.

In our study, the rate of bone union in the grafted area was $100 \%$. The union rate was superior to the rate reported in the best results of a previous Japanese study [9]. Now, the main problem was that of the adjacent disc degeneration. We found different progressive patterns of the disc degeneration according to the levels (upper or lower). The initial stage of disc degeneration was DSN. However after that, the progressive pattern of disc degeneration was different according to the adjacent levels (upper level or lower level). At the upper level, the intervertebral disc showed SIT, but the lower discs showed osteophyte formation, and occasionally lead to CSU (Fig. 3). Salvage surgeries were performed more frequently at the upper level than at the lower level at an average of 11.7 years after the initial operation (Table 2). Therefore clinically, the upper level is important because upper adjacent disc degeneration leads to the symptomatic disorders, which often require repeated surgery during the long-term follow-up.

Although ALIF provided satisfactory overall clinical results in the mid-term, the frequency of salvage surgeries was gradually increased due to the adjacent disc degeneration. A key decision of whether to prevent the adjacent disc degeneration during a long-term follow-up needs to be made.

\section{Conclusions}

Although ALIF provided satisfactory overall clinical results in the mid-term (until 10 years), clinical results of the long-term follow-up data became worse. We found different progressive patterns of disc degeneration according to the adjacent levels (upper or lower). The upper level is especially important because upper adjacent disc degeneration leads to symptomatic stenosis due to SIT, which often requires repeated surgery.

\section{Acknowledgements}

The authors would like to thank Professor Tomoatsu Kimura, Hirokazu Ishihara, Masanori Nobukiyo, Shoji Seki, and Yumiko Abe of the Department of Orthopaedics, University of Toyama, for providing clinical advice.

\section{REFERENCES}

1. Herkowitz HN, Kurz LT. Degenerative lumbar spondylolisthesis with spinal stenosis. A prospective study comparing decompression with decompression and intertransverse process arthrodesis. J Bone Joint Surg Am 1991;73:802-8.

2. Lee CK. Lumbar spinal instability (olisthesis) after extensive posterior spinal decompression. Spine (Phila Pa 1976) 1983;8:429-33.

3. Herron LD, Trippi AC. L4-5 degenerative spondylolisthesis. The results of treatment by decompressive laminectomy without fusion. Spine (Phila Pa 1976) 1989;14:534-8.

4. Carragee EJ. Single-level posterolateral arthrodesis, with or without posterior decompression, for the treatment of isthmic spondylolisthesis in adults. A prospective, randomized study. J Bone Joint Surg Am 1997;79:1175-80.

5. Deguchi M, Rapoff AJ, Zdeblick TA. Posterolateral fusion for isthmic spondylolisthesis in adults: analysis of fusion rate and clinical results. J Spinal Disord 
1998;11:459-64.

6. Greenough CG, Peterson MD, Hadlow S, Fraser RD. Instrumented posterolateral lumbar fusion. Results and comparison with anterior interbody fusion. Spine (Phila Pa 1976) 1998;23:479-86.

7. Schnee CL, Freese A, Ansell LV. Outcome analysis for adults with spondylolisthesis treated with posterolateral fusion and transpedicular screw fixation. J Neurosurg 1997;86:56-63.

8. Chow DH, Luk KD, Evans JH, Leong JC. Effects of short anterior lumbar interbody fusion on biomechanics of neighboring unfused segments. Spine (Phila $\mathrm{Pa}$ 1976) 1996;21:549-55.

9. Inoue S, Watanabe T, Hirose A, et al. Anterior discectomy and interbody fusion for lumbar disc herniation. A review of 350 cases. Clin Orthop Relat Res 1984;(183):22-31.

10. Takahashi K, Kitahara H, Yamagata M, et al. Longterm results of anterior interbody fusion for treatment of degenerative spondylolisthesis. Spine (Phila Pa 1976) 1990;15:1211-5.

11. Tsuji H. Lumbar spine instability and surgical strategy. In: Tsuji H, editor. Comprehensive atlas of lumbar spine surgery. St. Louis: Mosby-Year Book; 1991. p.12-27.

12. Motosuneya T, Asazuma T, Nobuta M, Masuoka K, Ichimura S, Fujikawa K. Anterior lumbar interbody fusion: changes in area of the dural tube, disc height, and prevalence of cauda equina adhesion in magnetic resonance images. J Spinal Disord Tech 2005;18:18-22.

13. Chen D, Fay LA, Lok J, Yuan P, Edwards WT, Yuan HA. Increasing neuroforaminal volume by anterior interbody distraction in degenerative lumbar spine. Spine (Phila Pa 1976) 1995;20:74-9.

14. Christensen FB, Karlsmose B, Hansen ES, Bünger CE. Radiological and functional outcome after anterior lumbar interbody spinal fusion. Eur Spine J 1996;5:293-8.

15. Tsuji H, Hirano N, Katoh Y, et al. Ceramic interspinous block (CISB) assisted anterior interbody fusion. J Spinal Disord 1990;3:77-86.

16. Tsuji H, Hirano N, Matsui H, et al. Effects of ceramic interspinous block on anterior lumbar interbody fusion. In: Tsuji H, Hirano N, Matsui H, et al., editor. Lumbar fusion and stabilization. Tokyo: Springer; 1994. p.220-6.

17. Ishihara H, Osada R, Kanamori M, et al. Minimum 10-year follow-up study of anterior lumbar interbody fusion for isthmic spondylolisthesis. J Spinal Disord 2001;14:91-9.

18. Kaplan EL, Meier P. Nonparametric estimation from incomplete observations. J Am Stat Assoc 1985;53:45781.

19. Taillard W. Spondylolisthesis in children and adolescents. Acta Orthop Scand 1954;24:115-44.

20. Kanamori M, Ishihara H, Kawaguchi Y, Yasuda T. Hshaped autologous bone graft associated with a ceramic interspinous block for the posterior lumbar fusion. J Jpn Soc Lumbar Spine Disord 2005;11:157-63.

21. Kanamori M, Ishihara H, Kawaguchi Y, Ohmori K, Shigeta T. Posterior decompression for lumbar stenosis with spondylolisthesis. Cent Jpn J Orthop Traumatol 2002;45:717-8.

22. Motomura H, Kanamori M, Nobukiyo M. The relationship between lumbar vertebral disc height on plain radiography and disc degeneration evaluated with magnetic resonance imaging. J Jpn Soc Lumbar Spine Disord 2001;7:126-31.

23. Dennis S, Watkins R, Landaker S, Dillin W, Springer D. Comparison of disc space heights after anterior lumbar interbody fusion. Spine (Phila Pa 1976) 1989;14:876-8.

24. Kumar A, Kozak JA, Doherty BJ, Dickson JH. Interspace distraction and graft subsidence after anterior lumbar fusion with femoral strut allograft. Spine (Phila Pa 1976) 1993;18:2393-400.

25. Meyerding HW. Spondylolisthesis. Surg Gynec Obstet 1932;54:371-7.

26. Panjabi MM, White AA. Kinematics of the spine. In: Panjabi MM, White AA, editors. Clinical biomechanics of the spine. Philadelphia: JB Lippincott; 1978. p.61-90.

27. Johnsson KE, Redlund-Johnell I, Udén A, Willner S. Preoperative and postoperative instability in lumbar spinal stenosis. Spine (Phila Pa 1976) 1989;14:591-3.

28. Phillips FM, Carlson GD, Bohlman HH, Hughes SS. Results of surgery for spinal stenosis adjacent to previous lumbar fusion. J Spinal Disord 2000;13:432-7.

29. Rahm MD, Hall BB. Adjacent-segment degeneration after lumbar fusion with instrumentation: a retrospective study. J Spinal Disord 1996;9:392-400.

30. Seitsalo S, Schlenzka D, Poussa M, Osterman K. Disc degeneration in young patients with isthmic spondylolisthesis treated operatively or conservatively: a longterm follow-up. Eur Spine J 1997;6:393-7. 